\title{
A CONSTRUÇÃo SOCIAL DO MERCADO DA CONSTRUÇÃO CIVIL NOS ANOS 2000: O CASO DA HABITAÇÃo E O PAPEL DO EsTAdo
}

\author{
Maria Chaves JARDIM* \\ Gabriela Lanza PORCIONATO**
}

\begin{abstract}
RESUMO: Considerando o crescimento do setor da construção civil no Brasil na primeira década dos anos 2000, o artigo estuda, a partir desse grande mercado, a construção social do mercado da habitação entre 2002-2012, tendo como argumento que este mercado estaria enraizado em variáveis sociais, em especial o papel do Estado. $\mathrm{O}$ artigo assume como hipótese a importância do Estado na construção do mercado habitacional naquela década, identificando diversas iniciativas, como a criação do Ministério das Cidades, em 2003, o investimento em habitação feito pelo Programa de Aceleração do Crescimento e a criação de um programa específico para a habitação, o Programa Minha Casa Minha Vida. Concluímos tratar-se de uma opção politica do grupo dirigente que esteva no poder naquele momento. Tem como inspiração teórica, conceitos da sociologia econômica, disciplina que tem buscado aproximar fenômenos ditos econômicos, como os mercados, de análises sociológicas.
\end{abstract}

PALAVRAS-CHAVE: Construção Social dos Mercados. Mercado da Construção Civil. Mercado da Habitação.

UNESP - Universidade Estadual Paulista "Júlio de Mesquita Filho". Faculdade de Ciências e Letras de Araraquara. Programa de Pós-Graduação em Ciências Sociais. Araraquara - SP - Brasil. 14800901 - majardim@fclar.unesp.br.

* UNESP - Universidade Estadual Paulista "Júlio de Mesquita Filho". Faculdade de Ciências e Letras de Araraquara. Programa de Pós-Graduação em Ciências Sociais. Araraquara - SP - Brasil. 14800901 - gabiporcionato@gmail.com 


\section{Introdução}

Nos anos 2000 o setor da construção civil teve uma ampla participação no Produto Interno Bruto (PIB) do país, partindo de um crescimento de $6,6 \%$, em 2004, para alcançar uma taxa recorde, de 11,6\%, em 2010, superando as taxas de crescimento nacional e mundial (7,5\% e 5,3\%, respectivamente) de acordo com o Instituto de Pesquisa Econômica Aplicada (IPEA DATA, 2012).

Ao analisar as séries de investimento bruto da economia brasileira no período 1947-2004, Morandi e Reis (2004) observam que o setor teve uma participação de $64 \%$ do investimento bruto total no período. Os autores afirmam que o valor adicionado da construção civil cresceu, em média, 19,6\% ao ano para no período de 1996-2007, sendo que o crescimento foi acentuado, a partir do ano de 2002, quando o regime de metas inflacionárias estava consolidado e teve início o processo de queda da taxa de juros básica. (IBGE, 2009a). No período de 2002-2007, a taxa de crescimento anual média do setor no País, se comparada à média para o total dos anos de 1996-2007, foi a mais elevada, 23\%. (FOCHEZATTO \& GHINIS, 2011).

É consenso que na década de 2000, especialmente entre 2004-2012, a atividade da construção civil cresceu significativamente, superando a década anterior (anos 1990) (HAGUENAUER et al., 2001); por outro lado, após o ano de 2012 o setor sofreu retração, com destaque para o ano de 2015, quando, segundo o IBGE (2015c), o setor teve uma retração de $16,5 \%$ em relação ao ano anterior.

Diante deste cenário, surgem explicações: para o IBGE (2009a), o setor foi influenciado pelo crescimento da renda familiar e do emprego, o aumento do crédito ao consumidor, a maior oferta de crédito imobiliário e a redução do Imposto sobre Produtos Industrializados (IPI) de diversos insumos da construção. Segundo Oliveira (2012), entre 2004-2012, o setor da construção civil foi prioridade na alocação dos recursos da economia e no fortalecimento do setor social, gerando emprego e renda. (BRASIL MTE, 2012). Nos anos de 2004, 2007 e 2010, o PIB da construção civil cresceu mais do que o PIB nacional. Em contraposição, no biênio 2014-2015 o segmento registrou queda de $8,6 \%$ (IBGE, 2015).

Trata-se de um setor que contribui para o desenvolvimento nacional e regional, já que a maior oferta de empregos formais é direcionada para a população mais carente, por ser um setor com grande empregabilidade de indivíduos com pouco grau de escolaridade. Assim, toda vez que esse setor está com taxas de crescimento significativas, temos a redução da desigualdade, com o aumento de renda da população pobre (JARDIM e PORCIONATO, 2014).

Considerando o contexto de crescimento do setor da construção civil no Brasil após 2004, assumimos como hipótese que a mão visível do Estado é uma variável fundamental para explicar a construção social desse mercado. Assim, sem 
ignorarmos a importância do empresariado da construção civil, nosso artigo tem como recorte analítico o papel do Estado, pois identificamos em nossa pesquisa, iniciativas estatais que ajudariam a explicar a construção social do mercado da construção civil: a criação do Ministério das Cidades (MC), em 2003, o investimento em habitação feito pelo Programa de Aceleração do Crescimento (PAC), a partir de 2007 e, finalmente, a criação de um Programa específico para a habitação, o Programa Minha Casa Minha Vida (PMCMV), em 2009, ajudariam a explicar esse forte mercado nos anos 2000.

Para realização da pesquisa, nos inspiramos nos marcos teórico da sociologia econômica; para coleta de dados, realizamos consultas em diversas fontes: relatórios do Tribunal de Contas da União, do PAC e do PMCMV.

Além dessa introdução e das considerações finais, o artigo é composto de duas seções. Na primeira seção apresentaremos os conceitos da sociologia econômica que nos ajudarão a compreender a construção social desse mercado. Na segunda seção, abordaremos os incentivos estatais ao mercado da habitação, tais como criação do MC, investimento do PAC no setor habitacional e a implantação do PMCMV.

\section{Enraizamento, Construção Social dos Mercados e Estado: a contribuição da sociologia econômica para a compreensão do mercado da habitação}

Abramovay (2004) conclui seu artigo considerado seminal na sociologia econômica, afirmando a existência de duas correntes extremas nos estudos sobre mercado: em uma corrente o mercado é enaltecido, na outra, demonizado. Este artigo busca estudar o mercado da construção civil, com foco na habitação, para além da dicotomia encontrada por Abramovay (2004), assim, nem sagrado e nem profano (JARDIM, 2015), apenas uma instituição histórica, localizada no tempo e no espaço e que se consolidou graças à mão visível do Estado, que regulou e estimulou esse mercado no período estudado.

Leituras que consideram que mercados são construídos socialmente, estão em direção oposta à doxa $a^{l}$ vigente na teoria econômica, a qual considera que mercados são apenas mecanismos de formação dos preços e, portanto, de alocação dos recursos, definindo a lei da oferta e da procura e produzindo o conceito de escassez. Tal perspectiva é largamente difundida nos cursos de ciências econômicas, estimulando os estudantes a encararem a economia como esfera autônoma da vida social e a enxergarem os indivíduos como um conjunto atomizado de sujeitos

\footnotetext{
1 Doxa é um ponto de vista particular, o ponto de vista dos dominantes, que se apresenta e se impõe como ponto de vista universal. (BOURDIEU, 2011, p. 120).
} 
egoístas. Como mostra Lebaron (2012), a visão mainstream de economia encontra eco nas escolas de economia dos Estados Unidos e tem formado os diretores e presidentes dos bancos centrais ao redor do mundo.

No Brasil, a Faculdade Getúlio Vargas seria a representante dessa versão que negligencia o mercado como fato histórico, composto pelas "motivações de homens e mulheres de carne e osso, cristalizadas em instituição". Essa perspectiva coloca o mercado e a concorrência como fenômenos a-sociais, já que a concorrência seria um estado de equilíbrio e não um processo. (JARDIM, CAMPOS, 2012, p.1).

Assim sendo, a Ciência Econômica promoveria profecias auto-realizantes (MERTON, 1968), tanto na esfera social quanto nas políticas públicas, produzindo mitos: no que se refere à vida econômica, os indivíduos são racionais, livres, interesseiros e procuram otimizar o emprego de seus recursos e, na medida em que podem agir em um ambiente de trocas e disputas livres de intervenções políticas, realizam a melhor forma possível de produção e distribuição dos recursos econômicos (JARDIM, 2015). A consequência desses mitos, é que opções políticas e econômicas se tornam naturalizadas, assim como a ordem social resultante destas, legitimando as desigualdades econômicas e sociais.

Visando questionar o consenso acima, a sociologia econômica, em diálogo crítico com a economia ortodoxa, tende a mostrar que os mercados podem ser estudados como estruturas sociais, ou seja, "formas recorrentes e padronizadas de relações entre atores, mantidas por meio de sanções" (SWEDBERG, 2003, p.255), ou mesmo como campo de força como sinalizou Bourdieu (2001).

De acordo com Abramovay (2004), o estudo dos mercados como estruturas sociais enraíza os interesses dos indivíduos nas relações que mantêm uns com os outros e não supõe um maximizador abstrato, isolado, por um lado, e a economia, por outro, como resultado mecânico da interação social. Da mesma forma, o estudo do mercado como campo, tal qual sugere Bourdieu (2001), pressupõe a interação entre agentes que possuem suas histórias de vida e seus dispositivos cognitivos $\left(\boldsymbol{h} \boldsymbol{a b i t u \boldsymbol { S } ^ { 2 }}\right)$, que por sua vez orientam suas preferências. Assim, tomadas de decisões, discursos e a criação de instituições são resultantes das ações dos agentes, inclusive do agente mais importante, o Estado. Bourdieu (2001) opta pelo conceito de campo $^{3}$, porque, segundo o autor, o conceito de mercado não permite identificar os inúmeros elementos humanos presentes no fenômeno econômico e nem a interação relacional entre as diversas instâncias da sociedade: a econômica, a social, a politica (Estado e seus agentes) e a religiosa; assim como a luta de atores para a imposição da doxa.

2 Para Bourdieu, habitus é um produto da história, resultado da socialização do agente.

3 Para Bourdieu, campo é o espaço social de relações de força entre diferentes agentes, providos de diferentes tipos de capitais. 
A construção social do mercado da construção civil nos anos 2000: o caso da habitação e o papel do Estado

Após esse enquadramento da abordagem teórica que nos inspira, passamos a apresentar os principais conceitos para a compreensão do problema de pesquisa.

\subsection{Enraizamento e construção social dos mercados}

Em A Grande Transformação, Polanyi (1980) argumentou que a economia de mercado não contém o conjunto das atividades necessárias à reprodução social e à sobrevivência humana, pois a autonomia do mercado conduziria à destruição social. Demonstrou que uma sociedade de automercado já nasceria fadada ao fracasso, pois retiraria toda a sua capacidade de coesão social e de solidariedade. A descrição do trabalho, da terra e do dinheiro como mercadorias seria fictícia, pois, mesmo sendo organizados em mercados, estes não são produzidos para a venda, mas para a reprodução da vida social (POLANYI, 1980).

Portanto, a sociedade de mercado é algo artificial, já que é necessário que a própria sociedade seja modelada para que o mercado possa funcionar. Para o autor "uma economia de mercado só pode funcionar em uma sociedade de mercado" (POLANYI, 1980, p.72). Essa constatação está em oposição aos estudos que colocam o mercado como uma esfera desenraizada do social. Nesse sentido, foi em um "contra movimento" que a sociedade autorizou a criação da economia de mercado, que só funciona, segundo o autor, porque está enraizada na sociedade. Logo, a economia de mercado não nasceu dos conceitos abstratos dos economistas e nem foi algo contra a vontade humana. É uma criação histórica, datada, cultural e humana.

Inspirado em Polanyi, Granovetter (2007) desenvolveu o conceito de enraizamento, dando maior ênfase do que Polanyi ao enraizamento do econômico no social. Para Granovetter (2007), se nas sociedades pré-mercantis, o comportamento econômico se encontrava imerso em relações sociais, nas sociedades modernas, a economia se torna uma esfera diferenciada: as transações econômicas não mais se definem por obrigações sociais, mas por cálculo racional voltado para maximizar o ganho. Contudo, o autor entende que os atores econômicos também orientam a sua conduta por objetivos que são sociais (como sociabilidade, reconhecimento, status, poder), logo, suas ações estão sempre enraizadas em redes sociais.

Nessa perspectiva, o mercado não seria um livre jogo de forças abstratas, de oferta e procura, entre atores atomizados, mas um conjunto de ações enraizadas em redes concretas de relações sociais. Para Granovetter (2007, p. 13), "fatos econômicos não ocorrem em um vazio, mas dentro de um marco social, composto por relações sociais variadas". Ampliando o conceito de enraizamento de Polanyi, para quem a sociedade de mercado se desenraizou da sociedade, Granovetter (2007) argumentou que o mercado estaria enraizado no social. 
Considerando os postulados da sociologia econômica, argumentamos que construções de mercados não se explicam apenas por variáveis econômicas, mas também por variáveis sociais e politicas. Nesse sentido, decisões econômicas e políticas não são frutos de agentes racionais, que isolados em seus escritórios e de sangue frio, buscam estrategicamente a solução ótima. Trata-se de agentes estatais, culturalmente socializados, de posse de suas disposições cognitivas, que realizam encontros oficiais e de corredores, que sofrem e que fazem sofrer na busca por uma solução que não necessariamente será a ótima (JARDIM, 2015). Assim, o mercado da habitação, estaria enraizado em variáveis sociais, em especial o Estado.

A seguir, outro conceito que nos ajuda a entender nosso tema.

\subsection{O Estado e seu poder simbólico}

Pierre Bourdieu é um autor bastante referenciado pela sociologia econômica que nos inspira nesta pesquisa, especialmente em seu livro, As Estruturas Sociais da Economia (2001), no qual, com base em pesquisas realizadas na França dos anos 1970 mostrou que o Estado contribuiu de forma decisiva na construção da demanda por casas. Isso ocorreu através da construção das disposições individuais dos consumidores e também na atribuição de recursos, concedendo auxílios para as construtoras.

Bourdieu (2001) demonstra que, ao destinar ajuda financeira aos construtores - por meio de créditos mais baratos e de incentivos à produção -, o Estado contribui para produzir o mercado de habitação, orientando direta ou indiretamente os investimentos financeiros. Assim, o Estado cria a oferta, via crédito fornecido pelos bancos públicos e ainda, por meio das campanhas publicitárias, ajuda a criar as disposições econômicas dos agentes compradores das casas.

As ideias de Bourdieu (2001) serão centrais para nos ajudar a pensar o papel do Estado no mercado da habitação no Brasil, já que define Estado como um espaço relativamente autônomo em relação às forças sociais em luta pelo poder, e que assegura uma posição de árbitro nos conflitos políticos. Dizer que o Estado é legitimo, é dizer que ele pode obter a submissão da ordem que impõe, tendo como forma de constrangimento o poder simbólico.

Assim, o Estado não tem a necessidade de dar ordens, ou de exercer coerção física para produzir um mundo social ordenado, pelo menos "enquanto puder produzir estruturas cognitivas incorporadas que estejam em consonância com as estruturas objetivas, assegurando assim a submissão dóxica à ordem estabelecida" (BOURDIEU, 2011, p. 119). 
Mais do que legislar nas questões econômicas e políticas, para Bourdieu (2011), o Estado legisla nas questões cognitivas, ou seja, na produção de crenças dos agentes, criando formas mentais de classificação, que serão usadas pelos agentes sociais. É considerando a importância do Estado não somente institucional, mas cognitivo - já que na nossa perspectiva o Estado influencia e é influenciado pelas formas de classificações dos agentes nele envolvido - que este artigo se apresenta. Mais do que legislar nas questões econômicas e políticas, o Estado teria legislado nas questões cognitivas, ou seja, na produção de crenças que auxiliaram na construção do mercado da habitação. Para Bourdieu (2011), um Estado que faz a violência simbólica não precisa fazer uso da violência física.

A seguir, as iniciativas do Estado, na construção desse mercado.

\section{A construção social do mercado da habitação nos anos 2000: a mão visível do Estado}

\subsection{A criação do Ministério das Cidades (MC) e de outras institucionalidades}

Logo após sua posse em 2003, o presidente Lula criou o Ministério das Cidades (MC), com os objetivos de combater as desigualdades sociais, transformar as cidades em espaços mais humanizados e ampliar o acesso à moradia, saneamento e transporte. No contexto, o ex-prefeito de Porto Alegre, Olívio Dutra, foi indicado para o cargo de Ministro. De acordo com Cardoso (2013), a equipe convocada para compor o ministério tinha fortes vínculos com o Fórum Nacional da Reforma Urbana $^{4}$ e já tinha participado de algumas experiências de administração local em Governos do Partido dos Trabalhadores (PT).

$\mathrm{O} \mathrm{MC}$ foi criado com o caráter de órgão coordenador, gestor e formulador da Política Nacional de Desenvolvimento Urbano, envolvendo, de forma integrada, as políticas ligadas à cidade. A criação desta instância veio a ocupar um vazio institucional no cenário nacional (CARDOSO, 2013), com o objetivo de integrar as áreas de habitação, saneamento ambiental e transporte urbano e mobilidade, tendo o uso e ocupação do solo como política transversal. O MC foi criado em diálogo com o Movimento Social da Reforma Urbana e buscou trabalhar de forma articulada com estados, municípios, movimentos sociais, Organizações não Governamentais (ONGs) e o setor privado, tendo na Caixa Econômica Federal (CEF) a operadora dos recursos (CAIXA, 2011).

4 Criado em 1987, visando promover a Reforma Urbana. 
Ao longo de 2003, a Secretaria Nacional de Habitação desenvolveu as bases normativas e institucionais da política habitacional, a saber, a Medida Provisória (MP) 252 e a Resolução 460. A MP 252 representou benefícios de renúncia fiscal, portanto, incentivou grande parte do setor imobiliário; a Resolução 460 do Conselho Gestor do Fundo de Garantia por Tempo de Serviço (FGTS) permitiu criar um sistema de descontos no FGTS, o que reduziu os custos de financiamento com os recursos do fundo, beneficiando os setores de baixa renda (CARDOSO, 2013).

Também fez parte desse contexto o surgimento do Programa Crédito Solidário em 2004, para atender as reivindicações de movimentos sociais. Trata-se de um programa voltado ao atendimento de necessidades habitacionais da população de baixa renda. O programa buscou a concessão de empréstimo direto ao beneficiário, para produção e aquisição de nova habitação ou para conclusão e reforma de moradias existentes (PORCIONATO, 2016).

No ano de 2005, foi aprovado um projeto de lei para a criação de um fundo de moradia, o Fundo Nacional de Habitação de Interesse Social (FNHIS). A lei que instituiu o FNHIS também estabeleceu as institucionalidades para a criação do Sistema Nacional de Habitação (SNH), que contou com atribuições aos três níveis de governo, dando destaque para os municípios (CARDOSO, 2013).

Portanto, a Resolução 460, que previa descontos do FGTS, somada à criação do FNHIS, marcou um momento inovador na política habitacional, que foi o compromisso do Governo Lula em subsidiar a produção de moradias para as camadas de baixa renda, atendendo a uma demanda que se manifestava a partir das críticas à atuação do modelo vigente, o Banco Nacional da Habitação (CARDOSO, 2013).

Para Maricato (2005), uma das conquistas mais importantes do Governo Lula foi a elaboração de um novo paradigma para estruturar o SNH, inspirado no Projeto Moradia, elaborado no ano de 2000, no Instituto Cidadania. A nova politica nacional de habitação previa a construção do MC e a elaboração de uma Política Urbana com as propostas de saneamento, transporte/trânsito e planejamento territorial, além da habitação.

A coordenação do Projeto Moradia foi da arquiteta e ex-deputada estadual pelo PT, Clara Ant, junto com André de Souza, ligado à Central Única dos Trabalhadores (CUT); além disso, o projeto contou com Ermínia Maricato, pesquisadora aposentada da Universidade de São Paulo (USP); Evaniza Rodrigues, mestre em Arquitetura pela USP, e consultora da CEF; Iara Bernardi, que foi Deputada Federal pelo PT, ligada às questões urbanas; Lúcio Kowarick, professor titular aposentado da USP e especialista em urbanização; Nabil Bonduki, professor da USP, especialista em planejamento urbano, relator do Plano Diretor e vereador pelo PT; e Pedro Martoni Branco, economista e diretor do Instituto Via Pública. 
As minibiografias acima indicam que a política urbana durante o período foi liderada por agentes com grande expertise no tema, por tratar-se de intelectuais que dedicaram suas carreiras às questões urbanas, portanto, à política urbana nelas inclusas. A questão da habitação do Governo Lula, foi resultado das visões de mundos de pessoas sensibilizadas pelo tema.

O Programa contou com a ampliação do mercado privado, via Parceria Público Privada (PPP), para que este atendesse a população com renda superior a 5 salários mínimos (SHIMBO, 2010). O setor privado deveria atender as demandas da classe média, para que os recursos financeiros federais ficassem concentrados nas faixas de renda situadas abaixo dos cinco salários mínimos, estrato onde se concentra $92 \%$ do déficit habitacional (MARICATO, 2005). Essa nova proposta preencheu a lacuna existente desde o fim do Banco Nacional da Habitação (BNH), em 1988, considerado falido para os coordenadores da nova política urbana, já que este colocou a habitação nas mãos dos bancos privados.

Entre 2005 e 2008, foram criados programas habitacionais para a população de até 3 salários mínimos mensais: Programa da Ação Provisão Habitacional de Interesse Social; Programa Urbanização, Regularização e Integração de Assentamentos Precários; e o Apoio à Produção Social de Moradia.

Mas foi a partir de 2004 que o mercado imobiliário habitacional experimentou uma fase de crescimento constante, com ampliação da produção e aumento dos preços. Para Cardoso (2013), tratou-se de uma profunda reestruturação do setor. A partir de 2004, algumas das maiores empresas da construção civil abriram capital na bolsa de valores. Os recursos obtidos nessas transações foram usados para ampliar suas atividades, assumindo controle acionário das empresas regionais, investindo em terra ou financiando novos empreendimentos.

Assim, já nos primeiros anos do $1^{\circ}$ Governo Lula (2003-2006), o Estado construiu as bases institucionais da política habitacional do período. Sob a aparência de neutralidade burocrática, o Estado impôs seus interesses, em diálogo com o Fórum das Cidades, com os movimentos sociais urbanos, com intelectuais sensíveis ao tema e com parcerias com o setor privado (bancos e grandes construtores).

A seguir, os incentivos financeiros estatais para o mercado da construção civil, via PAC.

\subsection{PAC: Eixo Infraestrutura Social e Urbano}

O PAC foi criado em 2007 e investiu volumosos valores no mercado da habitação. Trata-se de um conjunto de estratégias com o objetivo de promover o desenvolvimento, através da aceleração da economia e do aumento do emprego. 
A iniciativa esteve organizada em duas partes: a primeira reuniu os investimentos em infraestrutura e, a segunda, ações para ampliação do crédito. Além da promessa de estimular os setores produtivos, o PAC levou benefícios sociais para todas as regiões do país (BNDES, 2008).

Segundo dados do PAC (2010), de 2007 a 2010 foram investidos R \$ 503,9 bilhões em infraestrutura. Parte desse valor ( $\$$ 219,20 bilhões), foram investimentos feitos por empresas estatais e R $\$ 67,80$ bilhões foram investidos com recursos do Orçamento Fiscal da União (OFU) e da seguridade. O restante, R \$216,9 bilhões, foi investido pela iniciativa privada (empresas, fundos de pensão e fundos do mercado financeiro). Sobre os investimentos feitos pelos PAC, se somados o setor da infraestrutura social e urbana ( $\mathrm{R} \$ 170,8$ bilhões) com o setor de habitação (R\$ 106,3 bilhões), o mercado da construção civil foi o grande beneficiado do PAC e com ele, o mercado da habitação.

O PAC teve continuidade no governo de Rousseff (2011-2014), quando foi batizado de PAC2. Uma característica do PAC2 foi a ênfase na inclusão social dos pobres, por meio do eixo Comunidade Cidadã, assim como a continuidade do PMCMV. Uma novidade em relação ao PAC 1 foram os investimentos em obras para a Copa do Mundo (2010) e para as Olimpíadas (2012), alimentando ainda mais o setor da construção civil. A segunda etapa do PAC2 buscou fornecer infraestrutura por meio dos investimentos de cerca de R\$ 1 trilhão no período de 2011 a 2014. Estimativas indicam que $50 \%$ do total desse investimento foram direcionados para o setor de energia e 30\% para o PMCMV (JARDIM, 2015).

Esse destaque para o setor habitacional não deve ser isolado da criação do MC, em 2003, que fortificou institucionalmente o tema; é do mesmo período a criação das Conferências das Cidades, que é outro marco do período. Tanto a criação do MC, quanto das conferências das Cidades, assim como a implantação de projetos sociais ligados à habitação, foram efetivados pelo Governo Federal, em diálogo com os movimentos sociais ligados à cidade e com intelectuais sensíveis ao tema.

É no contexto de implantação do PAC, da criação do MC, que o Governo Lula implantou o Programa Minha Casa Minha Vida (PMCMV), que ajudou a consolidar o já fortalecido mercado da habitação.

\subsection{O PMCMV: papel do Estado}

O PMCMV foi criado em 2009, com o objetivo de reduzir o déficit habitacional do país, considerado pelo Governo Lula como um problema crônico nacional.

A criação do MC, em 2003, assim como o financiamento do mercado habitacional através do PAC, e demais programas criados fez parte das estratégias 
do Estado, visando a estimular a aquisição da casa própria junto às classes menos favorecidas.

A primeira menção ao programa se deu no $7^{\circ}$ Balanço do PAC (2009a). No $6^{\circ}$ Balanço do PAC (2009b), não havia menção ao PMCMV ainda, mas a apresentação do relatório já apontava que incentivos fiscais e financeiros para investimentos residenciais (habitação para famílias de baixa renda) estavam sendo formulados. A partir do $7^{\circ}$ Balanço (PAC, 2009a), notamos a mudança na nomenclatura do Programa para o título de Minha Casa Minha Vida.

De acordo com o Balanço, a alteração justifica-se pela necessidade em dar autonomia ao Programa e criar uma legislação que garantisse a ampliação da oferta de construções. Em 2009, foi criado o Programa, com a meta de construção de 1 milhão de moradias em curto prazo, com orçamento de R \$ 34 bilhões. (PORCIONATO, 2016). Além disso, previa a regularização fundiária de assentamentos localizados em áreas urbanas, alterando alguns decretos, leis e medidas provisórias anteriores (CARDOSO, 2013).

O PMCMV estabeleceu um patamar de subsídio direto, impactando a economia através dos efeitos multiplicadores gerados pelo mercado da construção. Além dos subsídios, aumentou o volume de crédito para aquisição e produção de habitação e reduziu os juros. Com a criação do Fundo Garantidor da Habitação (FGH), foram aportados recursos para pagamento das prestações em caso de inadimplência por desemprego ou outras eventualidades (CARDOSO, 2013).

Para a presidente Rousseff, foi o Programa que mais recebeu recursos do Orçamento e foi o primeiro Programa Federal que buscou dar respostas efetivas para o problema (BRAGA; CASTRO, 2014). Ainda para Rousseff, o Estado é central na resolução da questão da habitação, pois o mercado não é capaz de resolvê-lo. A partir do PMCMV, o Estado fixou as regras de funcionamento, com a implantação de um marco jurídico para o setor.

No contexto, o então Ministro da Fazenda, Guido Mantega, declarou que o PIB do país seria favorecido, pois o PMCMV era uma política anticíclica que ajudaria o país a crescer com solidez e baixos riscos. O Presidente do Sindicato da Construção Civil (SINDUSCON), também considerou o programa bem estruturado. Foi por meio do SINDUSCON-SP que seminários e debates foram elaborados visando a discutir os rumos da política habitacional nacional. (PORCIONATO, 2016).

De acordo com a Lei $\mathrm{n}^{\circ}$ 12.424-2011 e as Resoluções do Conselho Monetário Nacional, inicialmente eram 3 faixas que compunham as condições obrigatórias para o financiamento:

Faixa 1 - Famílias com renda mensal bruta de até $\mathrm{R} \$ 1.600$

Faixa 1.5 - Famílias com renda mensal bruta de até R\$3.275

Faixa 2/3 - Famílias com renda mensal bruta entre R\$3.275- R\$ 5 mil 
Para as famílias com renda de até 3 salários mínimos (Faixa 1), a meta foi construir 400 mil unidades habitacionais através do Fundo de Arrendamento Residencial (FAR), que recebeu recursos da Ouvidoria Geral da União (OGU) para viabilizar a construção de unidades habitacionais (CAIXA, 2011).

A execução das obras foi realizada por construtoras contratadas pela Caixa Econômica Federal (CEF), que se responsabilizaram pela entrega dos imóveis concluídos e legalizados, a partir da lista de demanda elaborada pelas prefeituras. Coube aos municípios cadastrar as famílias com rendimento de 0 a 3 salários mínimos, cujo cadastro deveria ser apresentado à CEF. No caso das faixas 1 e 1,5, devido ao valor do subsídio, que podia chegar até $90 \%$ do imóvel, era necessário ser sorteado para receber o imóvel.

O PMCMV também disponibilizou recursos para famílias com renda bruta de até $\mathrm{R} \$ 5.000,00$. Para esse grupo, os formatos e as taxas eram diferentes daquelas estabelecidas para as Faixas 1 e 1.5.

Assim, o PMCMV tinha três grupos de compradores, cada um respondendo a critérios específicos. O primeiro grupo era aquele que recebe até 3 salários mínimos e, para concorrer às casas populares, tinha que se inscrever nas prefeituras das cidades. As condições do segundo grupo eram muito parecidas daquelas do primeiro grupo, só aumentava o valor do imóvel. O terceiro grupo era aquele que recebia renda mensal de até $\mathrm{R} \$ 5.000,00$ e realizava a inscrição diretamente na agência da CEF. Trata-se de diferentes mercados em um mesmo mercado, o mercado da habitação, que, por sua vez, faz parte do grande mercado da construção civil.

A distribuição orçamentária dos recursos do FAR foi feita nos 27 Estados do Brasil, conforme a meta física de unidades habitacionais por Estado da Federação e considerando o cálculo do déficit habitacional. (CARDOSO, 2013).

De acordo com a CAIXA (2011), entre o PMCMV 1 e o 2 foram contratadas mais de 4 milhões de moradias. O Quadro 1 evidencia o número de moradias construídas por Estado. 
A construção social do mercado da construção civil nos anos 2000: o caso da habitação e o papel do Estado

\section{QUADRO 1: Moradias construídas por Estado}

\begin{tabular}{|c|c|c|c|}
\hline \multicolumn{2}{|c|}{ Norte } & \multicolumn{2}{|c|}{ Nordeste } \\
\hline$A C$ & 50 & $A L$ & 3.040 \\
\hline AM & 2.170 & BA & 14.715 \\
\hline AP & 580 & CE & 6.250 \\
\hline PA & 4.110 & MA & 6.740 \\
\hline RO & 1.490 & PB & 7.425 \\
\hline $\mathbf{R R}$ & 570 & PE & 4.750 \\
\hline TO & 4.680 & PI & 8.850 \\
\hline \multicolumn{2}{|c|}{ Sul } & $\mathbf{R N}$ & 5.690 \\
\hline PR & 5.128 & SE & 2.827 \\
\hline RS & 3.484 & & \\
\hline SC & 950 & \multicolumn{2}{|c|}{ Sudeste } \\
\hline \multicolumn{2}{|c|}{ Centro-Oeste } & ES & 1.417 \\
\hline GO & 4.885 & MG & 7.866 \\
\hline MS & 2.197 & $\mathbf{R J}$ & 581 \\
\hline MT & 4.140 & SP & 2.763 \\
\hline
\end{tabular}

Fonte: CAIXA - www.feiraocaixa2016.com.br.Acesso em: 5 jan. 2016.

Alguns dos Estados atingiram cotas muito altas de construção (Bahia e Piauí), enquanto outros ficaram muito abaixo do que foi estimado (Acre e Santa Catarina). Segundo Cardoso (2013, p. 36), no final de 2010, "alguns Estados reclamaram junto ao governo por terem já estourado a sua meta e não disporem de mais recursos, enquanto outros permaneceram aquém da meta original".

Entre 2009 e 2014, o PMCMV atendeu a 6,8 milhões de beneficiários. Desse total, $52 \%$ com renda até R \$ 1.600,00; 39\% com renda até R \$ 3.275,00 e $9 \%$ com renda de até R $\$ 5.000,00$. Os dados ${ }^{5}$ de 2016 mostram que 1,7 milhão de moradias foram entregues em 5.288 municípios. Foram gerados 1,3 milhão de empregos e 80 mil novas empresas de construção foram abertas. Dos R \$ 63 bilhões de renda gerados em toda a economia, R \$37,55 bilhões foram do setor da construção civil. Segundo Jardim (2015), para esses empregos, houve a orientação do Governo Federal para que as prefeituras priorizassem a mão-deobra de famílias beneficiadas pelo Programa Bolsa Família (PBF), inserindo essas pessoas no mercado de trabalho.

Em diálogo com a criação do $\mathrm{MC}$ e do investimento do PAC em habitação, o PMCMV ajudou a consolidar o mercado da construção civil, gerando emprego, renda e reduzindo a desigualdade social, além de realizar o sonho da casa própria

5 Disponível em: http://www.feiraodacaixa2016.com.br/cadastro-minha-casa-minha-vida-2013. Acesso em: 5 fev. 2016. 
para diversos grupos sociais, com destaque para famílias que ganhavam até três salários mínimos, consideradas a prioridades do Programa.

Após esse percurso macrossociológico, o próximo item busca conhecer os agentes que atuaram na criação do PMCMV. Isso é importante para entendermos as motivações desse grupo que elegeu o mercado da construção civil, com destaque para o mercado da habitação, como agenda central na primeira década dos anos 2000 .

\subsubsection{Agentes responsáveis pela criação do PMCMV}

O QUADRO 2 contém os nomes dos responsáveis pela implantação do PMCPM. São esses agentes que, orientados pelas grandes funções estatais, defenderam o mercado da habitação, em oposição à década anterior (1990), quando vigorava o modelo $\mathrm{BNH}$, considerado falido pelos movimentos sociais urbanos, pois o Estado esteve ausente da gestão da habitação via BNH.

\section{QUADRO 2: Comissão para implementação do PMCMC}

\begin{tabular}{|l|l|l|l|c|}
\hline \multicolumn{1}{|c|}{ Nome } & \multicolumn{1}{|c|}{ Formação } & \multicolumn{1}{c|}{ Profissão } & $\begin{array}{l}\text { Cargo durante a } \\
\text { implementação }\end{array}$ & $\begin{array}{c}\text { Partido } \\
\text { Político }\end{array}$ \\
\hline $\begin{array}{l}\text { Luiz Inácio Lula da } \\
\text { Silva }\end{array}$ & Curso Técnico & $\begin{array}{l}\text { Torneiro } \\
\text { Mecânico }\end{array}$ & $\begin{array}{l}\text { Presidente da } \\
\text { República }\end{array}$ & PT \\
\hline Tarso Genro & $\begin{array}{l}\text { Graduado, } \\
\text { especialista em } \\
\text { Direito Trabalhista }\end{array}$ & Advogado & M. Justiça & PT \\
\hline $\begin{array}{l}\text { Guido Mantega } \\
\text { Silva }\end{array}$ & $\begin{array}{l}\text { Graduado em } \\
\text { Economia, Doutor } \\
\text { em Sociologia }\end{array}$ & Economista & M. Fazenda & PT \\
\hline Carlos Minc & $\begin{array}{l}\text { Curso Superior } \\
\text { Incompleto }\end{array}$ & Bancário & $\begin{array}{l}\text { M. Planejamento, } \\
\text { Orçamento e } \\
\text { Gestão. }\end{array}$ & PT \\
\hline $\begin{array}{l}\text { Mestre, Doutor } \\
\text { Marcio Fortes de } \\
\text { Almeida }\end{array}$ & $\begin{array}{l}\text { Gesenvolvimento do } \\
\text { Graduado, Doutor } \\
\text { Diplomata }\end{array}$ & Economista & $\begin{array}{l}\text { M. Meio } \\
\text { Ambiente. }\end{array}$ & PT \\
\hline
\end{tabular}

Fonte: Dados da pesquisa. 
Ao elaborar a minibiografia dos principais responsáveis pelo PMCMC, identificamos que a comissão era composta majoritariamente por membros do PT, partido que historicamente manteve forte diálogo com os movimentos sociais, inclusive com os movimentos sociais ligados às cidades, em especial o Fórum Nacional da Reforma Urbana, com o qual os membros do Governo dialogaram para a construção do projeto de habitação. Com exceção de Marcio Fortes (PP), os demais membros sempre estiveram engajados com o tema do déficit habitacional, por intermédio do Instituto da Cidadania, onde Lula, então candidato à presidência em 2002, debateu e elaborou suas propostas de políticas públicas em diálogo com intelectuais engajados.

Portanto, o mercado da habitação seria resultado da visão de mundo dos agentes que compuseram o Governo Federal nos anos 2000, ou, nas palavras de Bourdieu (2011), resulta das disposições cognitivas (habitus) dos agentes, cujas disposições são construídas socialmente e acionadas, não necessariamente consciente, toda vez que um agente precisa tomar decisões.

Apresentar as minibiografias é importante porque nos ajuda a reforçar a ideia presente em Polanyi (1980) e Granovetter (2007), qual seja, de que mercados não estão desenraizados da sociedade, nem da história de vida dos agentes que os compõem (JARDIM, 2015). Assim, não é coincidência o fato de que são justamente agentes com histórico interesse pelas questões habitacionais, que levantaram essa bandeira, aquecendo não apenas o mercado da habitação, mas também o da construção civil. Como desdobramento, o Estado gerou emprego e renda para trabalhadores da construção civil, setor onde se encontra trabalhadores com menor nível de escolaridade, além de ajudar indivíduos de classes sociais desfavorecidas a adquirirem sua casa própria.

Como desdobramento das energias sociais dispendidas em torno do Programa, alguns meses depois da aprovação da MP, que colocou o PMCMV em vigor, 220 mil contratos já haviam sido assinados (PORCIONATO, 2016).

Diante do exposto, o mercado da habitação construído nos anos 2000, com especial estimulo do PMCMV, foi apoiado e controlado, direta e indiretamente pelo Estado. As motivações dos agentes que compuseram o Estado nesse período nos ajudam a entender a insistência do Estado brasileiro com a pauta da habitação. Afinal, antes de ser um projeto econômico, foi um projeto de um grupo, sensibilizado e interessado pelas questões de habitação. 


\section{Considerações Finais}

O artigo teve como tema de estudo a construção social do mercado da construção civil no Brasil, na primeira década dos anos 2000, com destaque para o mercado da habitação.

Após identificarmos a criação do MC, em 2003, o volumoso investimento do PAC direcionado à habitação a partir de 2007 e, finalmente, a criação do PMCMV, em 2009, defendemos que o Estado brasileiro viu no mercado da construção civil e da habitação diversas possibilidades: gerar emprego e renda para um grupo com baixa escolaridade - já que o setor da construção civil é o que mais emprega esse perfil de trabalhadores -; possibilitar a aquisição da casa própria para grupos historicamente excluídos do mercado da habitação e responder a uma reivindicação histórica do movimento social ligado às cidades, sobre o déficit habitacional.

Através de uma série de intervenções políticas, o Estado foi o responsável pela definição e a imposição das regras do mercado da construção: desde a criação do $\mathrm{MC}$, a aprovação de leis orçamentárias, a criação do PMCMV, os investimentos em infraestrutura via PAC, o controle dos meios de pagamento e o oferecimento de crédito via Caixa, até a formação da mão-de-obra, uma vez que para as obras do PAC, a orientação do Governo Federal era o uso da mão-de-obra dos beneficiários do PBF.

Com todas essas iniciativas, o Estado contribuiu para fertilizar o mercado da construção civil durante o período, em especial o mercado da habitação, criando as bases para a oferta e para a demanda no mercado, especialmente ao reformular sua política de incentivos à construção civil, dando foco à construção habitacional de padrão econômico. Este incentivo fez com que as construtoras começassem a produzir um tipo de habitação mais econômico que, através da melhoria de renda e facilidade de crédito e subsídios, repassados diretamente ao comprador, despertou o interesse das classes populares pela compra da casa própria. Assim, o Estado elaborou um novo paradigma para estruturar a Política Nacional de Habitação, para além do modelo então vigente, o BNH, evidenciando a mão visível do Estado na construção do mercado da habitação e da construção civil.

Quando buscamos entender os agentes estatais engajados nesse tema, identificamos tratar-se de um grupo dirigente oriundo do PT, com forte diálogo com os movimentos sociais e com intelectuais ligados às questões urbanas. Além disso, identificamos que o tema da habitação estava em discussão no PT desde os anos 1990, por meio do Instituto da Cidadania.

Em diálogo com as empresas privadas via PPP, o Governo Lula, composto por agentes que já possuíam alguma sensibilidade com o tema habitação, colocou essa pauta como central. Contudo, na nossa perspectiva, a prioridade dessa agenda 
não foi uma decisão técnica ou econômica. Mais do que isso, o tema da habitação dialogava diretamente com as motivações dos agentes que fizeram parte do Governo e também de alguns de seus interlocutores, como movimentos sociais ligados à cidade e o setor de construção. Nesse sentido, o mercado da construção civil e da habitação teria sido resultado das disposições cognitivas dos agentes estatais, portanto, o mercado esteve enraizado em elementos sociais e políticos, em diálogo com os conceitos de Enraizamento e de Estado apresentados no início desse texto.

\section{THE SOCIAL CONSTRUCTION OF THE CIVIL CONSTRUCTION MARKET IN THE YEARS 2000: housing AND THE ROLE OF THE STATE}

ABSTRACT: Considering the growth of the civil construction sector in Brazil in the first decade of the 2000s, this article studies, on the basis of this large market, the social construction of the housing market between 2002 and 2012, and argues that it might be rooted in social variables, in particular considering the role of the State. Taking as a hypothesis the importance of the State in the construction of the housing market in that decade, the article identifies several initiatives such as the creation of the Ministry of Cities in 2003, the investment in housing made by the Growth Acceleration Program and the creation of a specific program for housing, the Minha Casa Minha Vida Program. We conclude these constitute a political choice by the ruling party in power at the time. The article's theoretical inspiration comes from concepts of economic sociology, a discipline that has sought to link socalled economic phenomena, such as markets, to sociological analyzes.

KEYWORDS: Social Construction of Markets. Construction Market. Housing Market.

\section{REFERÊNCIAS}

ABRAMOVAY, Ricardo. Entre Deus e o Diabo. Tempo Social: Revista de Sociologia da USP, São Paulo, v.16, n.2, p.35-64, 2004.

BOURDIEU, Pierre. As Estruturas Sociais da Economia. Lisboa: Instituto Piaget, 2001. BOURDIEU, Pierre. Razões práticas: Sobre a teoria da ação. 11 ed. Campinas, SP: Papirus, 2011. 
BRASIL, Ministério do Trabalho e Emprego (TEM) - Câmara Brasileira da Indústria da Construção Civil (CBIC). Relação Anual de Informações Sociais (RAIS), 2012. Disponível em: www.rais.gov.br. Acesso em: 22 ago. 2012.

BNDES. RELATÓRIO ANUAL BNDES. Rio de Janeiro: Banco Nacional de Desenvolvimento Econômico e Social, 1983. Anual. Continuação de Relatório das Atividades BNDE. 2008.

BRAGA, Mário; CASTRO, José Roberto. Dilma destaca Minha Casa como maior programa do governo. Estadão. São Paulo, 2014. Disponível em: http://politica.estadao.com.br/ noticias/geral,dilma-destaca-minha-casa-como-maior-programa-do-governo, 1144908. Acesso em: 11 mai. 2014.

CAIXA. Demanda habitacional no Brasil. Caixa Econômica Federal. Brasília: CAIXA, 2011. Disponível em: https://www.pdf-archive.com/2012/09/26/demanda-habitacional2/. Acesso em: 1 dez. 2017.

CARDOSO, Adauto L. (Org.). O Programa Minha Casa Minha Vida e seus Efeitos Territoriais. Rio de Janeiro: Letra Capital, 2013.

FOCHEZATTO, Adelar; GHINIS, Cristiano Ponzoni. Tendências e determinantes da produção da construção civil no Brasil e no Rio Grande do Sul nas duas últimas décadas: evidências da análise de dados em painel. Ensaios FEE, Porto Alegre, v. 31, 2011.

GRANOVETTER, M. Ação Econômica e Estrutura Social: o Problema da Imersão. RAE-revista de administração de empresas - eletrônica vol. 6, n. 1, janeiro-junho 2007. Disponível em: http://rae.fgv.br/rae-eletronica/vol6-num1-2007/acao-economica-estruturasocial-problema-imersao. Acesso em: 20 jul. 2017.

HAGUENAUER, Lia; BAHIA, Luiz Dias; CASTRO, Paulo F. de; RIBEIRO, Márcio B. Evolução das Cadeias Produtivas Brasileiras na Década de 90. Texto para discussão. Brasília, n. 768, abr. 2001.

IBGE. Instituto Brasileiro de Geografia e Estatística. Pesquisa anual da indústria da construção. Rio de Janeiro, v. 19, p. 1-98, 2009. Disponível em: https://biblioteca.ibge.gov. br/index.php/biblioteca-catalogo?view=detalhes\&id=754. Acesso em: 18 mai. 2017.

IBGE. Instituto Brasileiro de Geografia e Estatística. Pesquisa anual da indústria da construção. Rio de Janeiro, v. 22, p. 1-98, 2012. Disponível em: https://biblioteca.ibge.gov. br/index.php/biblioteca-catalogo?view=detalhes\&id=754. Acesso em: 18 mai. 2017.

IBGE. Instituto Brasileiro de Geografia e Estatística. Pesquisa anual da indústria da construção. Rio de Janeiro, v. 25, p.1-52, 2015. Disponível em: https://biblioteca.ibge.gov. br/index.php/biblioteca-catalogo?view=detalhes\&id=754. Acesso em: 18 mai. 2017. 
A construção social do mercado da construção civil nos anos 2000: o caso da habitação e o papel do Estado

IPEA DATA. Dados Brasil. Instituto de Pesquisa Econômica Aplicada, 2012. Disponível em: http://www.ipeadata.gov.br/ExibeSerie.aspx?serid=38414. Acesso em: 10 jul. 2017.

JARDIM. Maria. A construção social do mercado de trabalho no setor de construção civil nas obras do Programa de Aceleração do Crescimento (PAC): consensos e conflitos. Sociedade e Estado. Brasília, n.1, v.30, 165-187, 2015.

JARDIM, Maria; CAMPOS, Ricardo. A Construção social dos mercados e a crítica da Ciência Econômica. REDD - Revista Espaço de Diálogo e Desconexão, Araraquara, v. 4, n. 2, 1-9. 2012. Disponível em: http://seer.fclar.unesp.br/redd/article/viewFile/5174/4239. Acesso em: 10 jul. 2017.

JARDIM, Maria; PORCIONATO, Gabriela. O mercado de trabalho gerado pelas obras do PAC e Araraquara. In: CASAGRANGE, Elton; JARDIM, Maria (Org.). Araraquara dos anos 2000. 1 ed., São Paulo: Cultura Acadêmica, 2014. p. 81-100.

LEBARON, Frédéric. A formação dos economistas e a ordem simbólica mercantil. REDD Revista Espaço de Diálogo e Desconexão, Araraquara, v. 4, n. 2, jan/jul. 2012.

MARICATO, Ermínia. A Nova Política Nacional de Habitação. Folha de S. Paulo, 24 novembro 2005. O Valor, 5-9.

MERTON, Robert. Theory and Social Structure. New York: Free Press, 1968.

MORANDI, L.; REIS E. J. Estoque de capital fixo no Brasil - 1950-2002. XXXII Encontro Nacional de Economia - ANPEC, 07-10 de dezembro, João Pessoa, 2004. Disponível em: $<$ http://www.anpec.org.br/encontro2004/artigos/A04A042.pdf> Acesso em: nov. 2016.

OLIVEIRA, Valéria. O papel da Indústria da Construção Civil na organização do espaço e do desenvolvimento regional. $4^{\mathbf{0}}$ Congresso Internacional de Cooperação UniversidadeIndústria. 2012, Taubaté.

PAC. PROGRAMA DE ACELERAÇÃO E CRESCIMENTO. $11^{\circ}$ Balanço Completo do PAC - 4 anos (2007 a 2010). Ministério do Planejamento, 2010. Disponível em: http:// www.pac.gov.br/sobre-o-pac/publicacoesnacionais. Acesso em: 1 dez. 2017.

$7^{\circ}$ Balanço Completo do PAC (Janeiro - Abril de 2009). Ministério do Planejamento, maio de 2009a. Disponível em: http://www.pac.gov.br/sobre-o-pac/ publicacoesnacionais. Acesso em: 1 dez. 2017.

. $6^{\circ}$ Balanço Completo do PAC 2 - 2 anos (fevereiro 2009). Ministério do Planejamento, fevereiro de 2009b. Disponível em: http://www.pac.gov.br/sobre-o-pac/ publicacoesnacionais. Acesso em: 1 dez. 2017.

POLANYI, K. A grande transformação: as origens da nossa época. Tradução de Fanny Wrobel. Rio de Janeiro: Campus, 1980. 
PORCIONATO, Gabriela. Programa Minha Casa Minha Vida: a construção social de um mercado. Dissertação (Mestrado) - Programa de Pós-Graduação em Ciências Sociais, UNESP. Araraquara, 2016.

SHIMBO, Lucia Z. Habitação Social, Habitação de Mercado: a confluência entre estado, empresas construtoras e capital financeiro. 2010, 398f. Tese (Doutorado) - Universidade Federal de São Carlos-UFSCAr.

SWEDBERG, R. A Nova Sociologia Econômica: o que já se atingiu, o que se seguirá?. In: PEIXOTO, J.; MARQUES, R. (Org.). A Nova Sociologia Econômica. Lisboa: Celta, 2003. p.235-255.

Recebido em 14/08/2017.

Aprovado em 23/11/2017. 